(C) 1991 IEEE. Personal use of this material is permitted. However, permission to reprint/republish this material for advertising or promotional purposes or for creating new collective works for resale or redistribution to servers

or lists, or to reuse any copyrighted component of this work in other works must be obtained from the IEEE.

\title{
Accelerated Radioactive Beams at TRIUMF
}

\author{
J. D'Auria \\ Simon Fraser University, Burnaby, B.C., Canada V5A 1S6, \\ L. Buchmann, J.S. Fraser and H. Schneider \\ TRIUMF, 4004 Wesbrook Mall, Vancouver, B.C., Canada V6T $2 A 3$
}

\section{Abstract}

An isotope separator (TISOL) has been installed at TRI$\mathrm{UMF}$ to study the generation of radioactive beams for use in an accelerated radioactive beams facility (ISAC). As part of this program a single staged ECR ion source has been designed and connected to the isotope separator. This source is now operational and delivering radioactive ions extracted from the production target. Accelerator studies have shown that a superconducting interdigital structure is an attractive alternative to the room temperature DTL of the original ISAC proposal. The recently demonstrated high gradients in a RFQ test structure hold promise for the development of a RFQ suitable for the initial stage of ISAC.

\section{INTRODUCTION}

In recent years many proposals for building an accelerated radioactive beams facility based on an isotope separator have evolved. One of these propsals has been the ISAC facility [1-3] at TRIUMF where a test facility for the front end of a radioactive beams facility $h$ as been built (TISOL). At the same time studies have continued to optimize the postaccelerator design.

The isotope separator is in its second year of operation. A major beam line extension is now in progress which will allow experiments at TISOL to begin this summer.

\section{The Isotope Separator Tisol}

\section{A. TISOL Layout}

TISOL is a thick target (several $\mathrm{g} / \mathrm{cm}^{2}$ ) isotope separator $[4,5]$ located at a $500 \mathrm{MeV}$ proton beam line of the TRIUMF cyclotiron.

Figure 1 displays an overview of the expanded TISOL facility, to be assembled by May 1991, however, the data reported here were taken at another (lower) collection point.

The TISOL facility consists of the following components: A thick target in an oven, heatable up to $2000^{\circ} \mathrm{C}$, a transfer line, an ion source (shown here is the ECR configuration), the extraction electrode system, including an einzel lense, two magnetic quadrupoles, a magnetic steerer doublet, a mass analysing magnet, resolution defining slits and an electrostatic beam transport system. The extraction voltage of the system is typically $18 \mathrm{kV}$. The mass resolution $(\mathrm{M} / \Delta \mathrm{M})$ of the analysing magnet has been determined to be $1000-3000$ depending on the slit setting. The electrostatic quadrupole system consists of a number

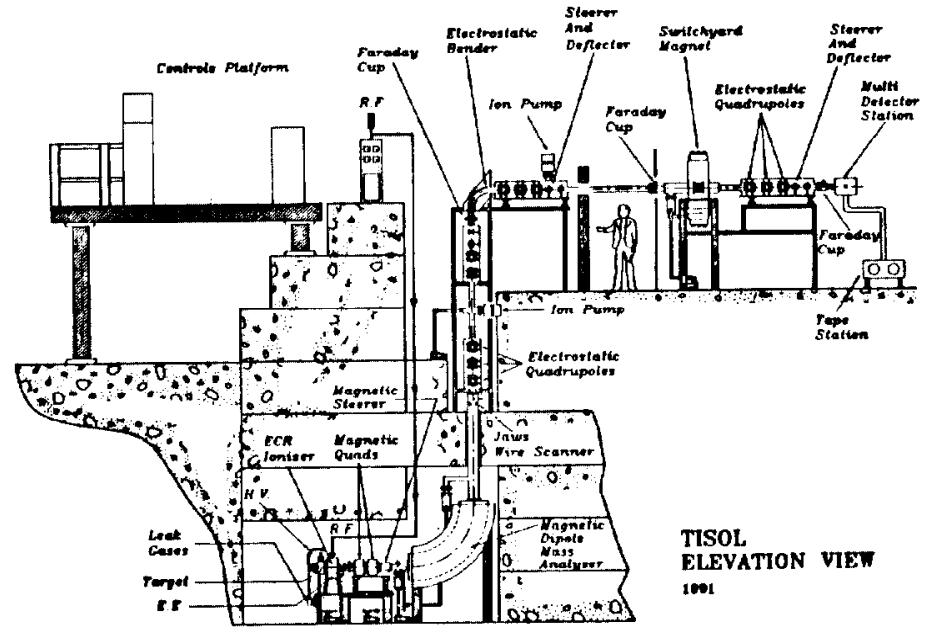

Figure 1. Overview of the TISOL facility as planned for May 1991. $\mathrm{NB}$ that the actual position of the beam lines is somewhat different from this schematic layout. A description of the facility is given in the text.

of electrostatic quadrupole triplets/doublets and steerers. 'The beam can be directed into one of three beam lines via a switching magnet. Several Faraday cups and wire scanners serve for beam diagnosis.

Targets of Ta, Hf, Ti, $\mathrm{Nb}, \mathrm{Zr}, \mathrm{SiC}, \mathrm{ScC}, \mathrm{ZrC}, \mathrm{UO} / \mathrm{C}$, $\mathrm{MgO}, \mathrm{CaO}, \mathrm{LaC}_{2}, \mathrm{AlN}, \mathrm{NaAlSiO}_{4}$ have been explored under varying conditions. For the surface ionization source radioactive species of $\mathrm{Li}, \mathrm{Na}, \mathrm{Al}, \mathrm{K}, \mathrm{Rb}, \mathrm{Sr}, \mathrm{Ga}$, In, $\mathrm{Cs}, \mathrm{Yb}$, Fr have been observed by their characteristic $\beta \gamma$-decays. A new design of a surface ionization source is in development.

At present proton beam currents are limited to $0.5 \mu \mathrm{A}$ because of target activation and handling considerations. To increase the current a better target handling system is under construction.

\section{B. The ECR Ion Source}

An overview of the ECR source including the target system is given in Fig. 2.

The ion source consists of two quartz tube liners, with the inner one being the plasma chamber with the rf coupled in radially. An iron yoke is used in the generation of the magnetic field, with the ECR mirror condition being axially produced by an iron ring in the middle of the source. Radial electron confinement is provided by a SmCo hexapole (surface field $0.52 \mathrm{~T}$ ). The source is presently operated at $6 \mathrm{GHz}$, but can be used up to a maximum frequency of $10 \mathrm{GHz}$. 


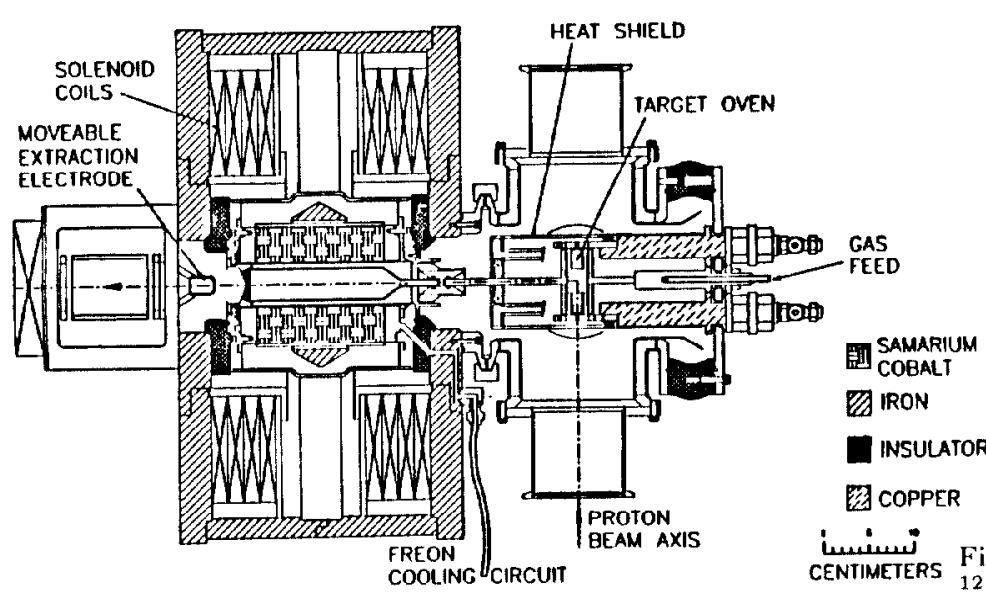

Figure 2. Top vicw of the TISOL ECR system as described in the text.

The inner quartz tube can be removed together with the coupling piece to the target assembly. Due to heat problems and resulting sparking the plastic insulation at the coupling end is cooled by a closed freon circuit. The target unit can be easily pulled away from the coupling.

The target unit is mounted on a flange consisting of the heatable oven and the watercooled transfer line as well as several service connections. A $7.5 \mathrm{~cm}$ long graphite cylinder resistively heated serves as the oven with the target of choice being contained in a $5.5 \mathrm{~cm}$ long graphite crucible. Radioisotopes released by the target matrix diffuse through the transfer line into the ECR plasma chamber. Watercooling of the transfer line provides partial chemical selection. It is possible to add several gases to this chamber with the gas being fed through the target unit. Quite extensive watercooling is necessary for all parts of the target chamber which are not deliberately heated.

The source has been tested with several gases. Ionization efficiencies of up to $30 \%$ for stable neon have been observed. Radioactive isotopes of $\mathrm{He}, \mathrm{C}, \mathrm{N}, \mathrm{O}, \mathrm{Ne}, \mathrm{Cl}$, $\mathrm{Ar}, \mathrm{Kr}$, and $\mathrm{Xe}$ have been detected, partially as molecular, partially also as multiply charged species. Figure 3 shows yields of radioactive noble gases, multiply charged. 'These yields make it a viable option to consider the acceleration of heavy masses using multiply charged ions to start with. Many of the yields obtained exceed those reached at the separator ISOLDE at CERN [6].

\section{ili. Accelerator Studies}

A room temperature linac was originally proposed for ISAC $[2,7,8]$. It consists of an RFQ to capture, bunch and preaccelerate the very low energy, singly charged ions from the isotope separator to $60 \mathrm{keV} / \mathrm{u}$, followed by a stripper to increase the ion charge to mass ratio to at least $q / A=1 / 20$, before further acceleration in a Wideroë type drift-tube linac (DTL) to a final energy of $1 \mathrm{MeV} / \mathrm{u}$. This conventional room temperature structure would have required more than $1 \mathrm{MW}$ of $\mathrm{cw}$ rf power.

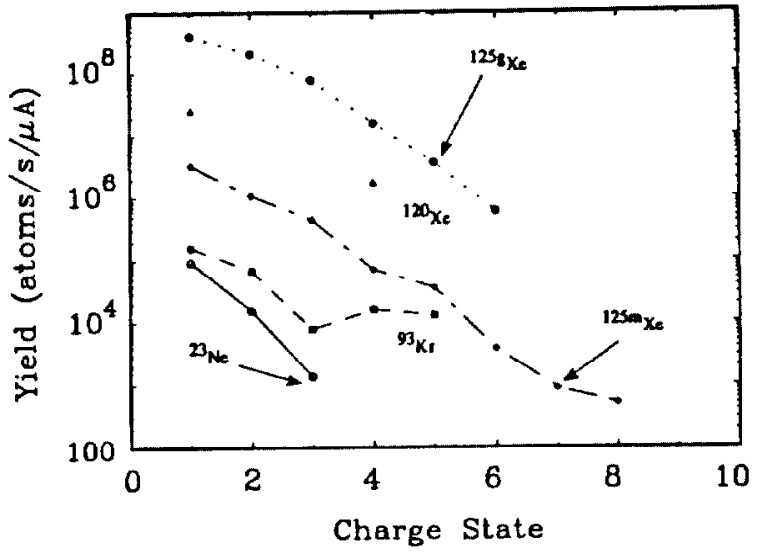

Figure 3. Yields for the radioactive isotopes of ${ }^{125 g} \mathrm{Xe},{ }^{125 m} \mathrm{Xe}$, ${ }^{120} \mathrm{Xe},{ }^{93} \mathrm{Kr}$, and ${ }^{23} \mathrm{Ne}$ up to a charge state of $8^{+}$extracted from either a $\mathrm{LaC}_{2}$ or a $\mathrm{UO}_{2}$ target.

\section{A. A Superconducting Interdigital Accelerator Structure}

In recent years significant progress has been made in the development of superconducting accelerator structures, in particular at the Argonne National Laboratory (ANL). By using an interdigital structure similar to that of the ANL ATLAS linac, it has been found possible to develop a conceptual design of a superconducting linac to replace the D'IL of the original ISAC proposal $[9,10]$.

Beam dynamics calculations were performed with the code PARMION which is a modification of the PARMELA code. The code uses tabulated rf field values in the cells for integration of the particle equations of molion through the linac. It accepts particles of arbitrary charge to mass ratios. Four contiguous cells are treated as a tank in which the acceleration field is constant and the entrance phase of the reference particle can be specified at each cell.

The complete SC DTL consists of twelve $50 \mathrm{MHz}$ tanks with six-intertank solenoids, contained in two cryostats each about two metres long, followed by $21100 \mathrm{MHz}$ tanks with seven solenoids in four two metre cryostats. The overall length of the DTL is $16.3 \mathrm{~m}$ with an output energy of 1.6 $\mathrm{MeV} / \mathrm{u}$ for masses $\mathrm{A} \leq 60$; the overall accelerating gradient is about $1.9 \mathrm{MV} / \mathrm{m}$.

\section{B. Development of Superconducting RFQ's}

$\mathrm{J}$. Delayen et al.[11,12] have recently reported achieving surface fields in excess of $100 \mathrm{MV} / \mathrm{m}$ in a superconducting niobium test structure designed to simulate a RFQ geometry. Such fields are about ten times larger than those considered in the earlier room temperature RFQ for ISAC and suggest interesting alternatives for the initial acceleration stage.

Not only do the higher fields make possible shorter RFQ's, but also because the focussing strength is proportional to $\lambda^{2} V$, where $\lambda$ is the of wavelength and $V$ the vane voltage, higher frequency operation is also possible.

Schempp et al.[13] have explored a number of RFQ design possibilities utilizing the higher gradients of the superconducting structures. They find for example a linac for radioactive ions proposed at ISOLDE/CERN would need 
to be only 7 metres in length to accelerate singly charged ${ }^{27} \mathrm{Al}$ to $1 \mathrm{MeV} / \mathrm{u}$, if one assumes maximum surface fields of $130 \mathrm{MV} / \mathrm{m}$. For the ISAC accelerator we find that for a more conservative assumption of $50 \mathrm{MV} / \mathrm{m}$ a $\mathrm{RFQ}$ to accelerate singly charged ${ }^{60} \mathrm{Ar}$ to $60 \mathrm{keV} / \mathrm{u}$ could be operated at $50 \mathrm{MHz}$ and would be only 2.25 metres long. For comparison, the room temperature RFQ studied earlier would have been 9 metres long and operated at $23 \mathrm{MHz}$. Table 1 lists some of the principal design parameters for the superconducting $R F Q$.

Table 1. Basic design parameters for a $50 \mathrm{MHz} \mathrm{SC}$ RFQ for ISAC.

\begin{tabular}{lr}
\hline \hline Ion & ${ }^{60} \mathrm{Ar}^{+}$ \\
Frequency & $50 \mathrm{MHz}$ \\
Input Energy & $1 \mathrm{keV} / \mathrm{u}$ \\
Output Energy & $60 \mathrm{keV} / \mathrm{u}$ \\
Vane Voltage & $158 \mathrm{kV}$ \\
Minimum Aperture Radius & $0.3 \mathrm{~cm}$ \\
Number of Cells & 196 \\
Normalized Emittance & $\mathbf{1 9}$ \\
Capture Efficiency & $0.5 \%$ \\
\hline \hline
\end{tabular}

IV. CONCLUSION

With the variety of source and accelerator developments that have taken place over the last couple of years the ISAC proposal has come to age and needs updating. For example, the remote handling of an ECR source has to be taken into consideration.

However, most excitingly, the development of superconducting heavy ion accelerators has changed the possible layout of the postaccelerator. Its design is now far less fixed than it was five years ago, as SC RFQ's have to be fully explored both in computer simulations as well as with some initial devices.

In North America a collaboration called IsoSpin Laboratory (ISL) has been founded [14] with some 200 scientists signed up working actively on a proposal for a radioactive beams facility which goes beyond the scope of the original ISAC proposal. Specifically an energy of $10 \mathrm{MeV} / \mathrm{u}$ for the radioactive ions is asked for with the possibility of accelerating masses up to $\mathrm{A}=240$, though not necessarily injecting

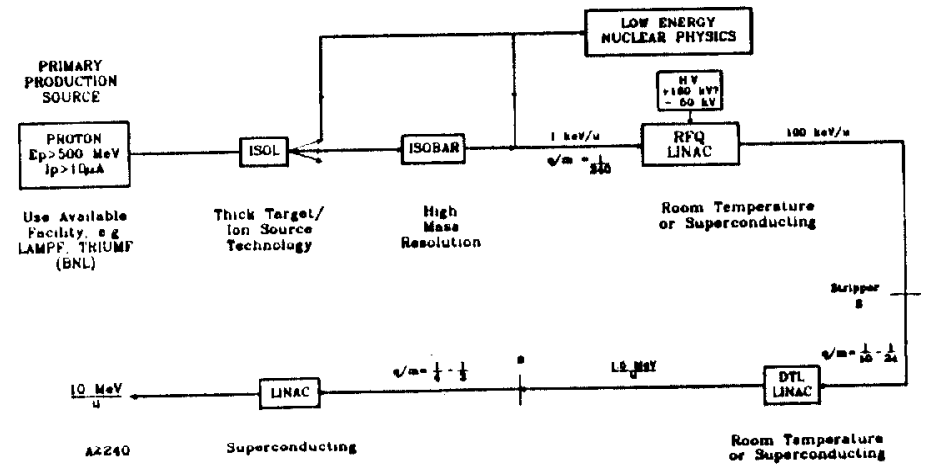

Figure 4. A benchmark facility for radioactive beams as proposed by the ISL initiative. these high masses as singly charged ions. Figure 4 shows a benchmark facility being proposed as a North American radioactive beams factory. The development of SC RFQ's may tie such a facility smoothly into the present plans for ISAC.

\section{REFERENCES}

[1] J.E. Crawford, J.K.P. Lee, R.B. Moore, H. Dautet, F. Buchinger, K. Oxorn, L. Nikkinen, J.M. D'Auria, L. Buchmann, J. Vincent and J. King, Nucl. Inst. Meth., B26, p. 128, 1987.

[2] L. Buchmann, J.M. D'Auria, J.D. King, G. Mackenzie, H. Schneider, R.B. Moore and C. Rolfs, Nucl. Inst. Meth., B26, p. 151, 1987.

[3] J.M. D'Auria, M. Dombsky, L. Buchmann, J.D. Vincent and J.D. King, Nucl. Inst. Meth., B40/41, 418, 1989.

[4] M. Dombsky, J.M. D'Auria, L. Buchmann, H. Sprenger, J. Vincent, P. McNeely and G.R. Roy, Nucl. Inst. Meth., A295, 291, 1990.

[5] L. Buchmann, J. Vincent, H. Sprenger, M. Dombsky, J.M. D'Auria, P. McNeely and G. Roy, submitted to Nucl. Inst. Meth., 1991.

[6] ISOLDE Users Guide, CERN 86-05 (1965, 1986 update).

[7] H.R. Schneider, G.E. McMichael, B.G. Chidley and R.M. Hutcheon, Proc. Accelerated Radioactive Beams Workshop, TRIUMF Report. TRI-85-1, 1985, p. 189.

[8] B.G. Chidley, R.M. Hutcheon and G.E. McMichael, Proc. 1986 Linac Conf., SLAC-303, 1986, p. 361.

[9] J.S. Fraser, J. D'Auria, L. Buchmann and H.R. Schneider, Proc. First Int. Conf. on Radioactive Nuclear Beams, Berkeley (World Scientific, 1989) p. 553.

[10] J.S. Fraser and H.R. Schneider, Proc. 1990 Linac Conf. Los Alamos, LA 12004-C, 1990, p. 88.

[11] J.R. Delayen and K.W. Shepard, Proc. 1990 Linac Conf. Los Alamos, LA 12004-C, 1990, p. 76.

[12] J.R. Delayen, C.L. Bohn and C.T. Roche, Proc. 1990 Linac Conf. Los Alamos, LA 12004-C, 1990, p. 82.

[13] A. Schemp, H. Deltinghoff, J.R. Delayen and K.W. Shepard, Proc. 1990 Linac Conf. Los Alamos, LA 12004-C, 1990 , p. 79.

[14] J. D'Auria and L. Buchmann, Nucl. Inst. Meth, in press (1991). 